\title{
Editorial
}

\section{eCAM: Early Harvest}

\section{Edwin L. Cooper}

\author{
Laboratory of Comparative Neuroimmunology, Department of Neurobiology, David Geffen School of Medicine \\ at UCLA, University of California, Los Angeles, Los Angeles, CA 90095-1736, USA
}

It may be considered a bit early to write or even think about harvest, with blazing sun and heat in some regions. In all parts of the world, autumn comes after summer in various guises - color of leaves, bringing in the 'sheaves': we are now in the midst of summer. Through good fortune and health and international cooperation, I feel extremely enthusiastic to report two bits of harvest this summer, one of which will be discussed in the last editorial 5/4: (i) translations of selected papers in Spanish and (ii) aspects of impact factor, both pro and con. Suffice it to mention that there was considerable euphoria when we received the news that $e C A M$ has been assigned the impact factor score of 2.535, making it the best journal internationally that publishes research articles in integrative medicine. Impact factor, like peer review and other measures of human creativity, signify worth and promise.

Now for the early harvest. A selection of $e C A M$ articles continue to be translated into Spanish for the Journal Digitalis. Expanding the influence of $e C A M$ by these translations is significant for a large block of people: Spain, Latin America, despite the preponderance of English in the scientific literature. Selected articles for the latter half of 2008 are listed below:

(i) Ayurveda and traditional Chinese medicine: a comparative overview. Available at: http:// ecam.oxfordjournals.org/cgi/content/full/2/4/465

(ii) Investigating acupuncture using brain imaging techniques: the current state of play. Available at: http://ecam.oxfordjournals.org/cgi/reprint $/ 2 / 3 /$ 315.pdf

For reprints and all correspondence: Edwin L. Cooper, Laboratory of Comparative Neuroimmunology, Department of Neurobiology, David Geffen School Of Medicine at UCLA, University of California, Los Angeles, Los Angeles, CA 90095-1763, USA. Tel: (310) 825-9567; Fax: (310) 825-2224; E-mail: ecam@mednet.ucla.edu (iii) The life threatened child and the life enhancing clown: towards a model of therapeutic clowning. Available at: http://ecam.oxfordjournals.org/cgi/ content/full/5/1/17

(iv) Standardization of nomenclature in acupuncture research (SoNAR). Available at: http://ecam. oxfordjournals.org/cgi/content/full/4/2/267

(v) Electro-acupuncture in relieving labor pain. Available at: http://ecam.oxfordjournals.org/cgi/ reprint $/ 4 / 1 / 125$

This latest selection will appear online between now and the end of December 2008 - an issue of Digitalis is published each month and is available at: http://www. e-digitalis.com.

To draw attention to the influence that results from publishing in $e C A M$, I chose to mention the work of Olalde and colleagues. For this editorial, I consulted with editorial board member Jose Olalde and Oswaldo del Castillo; therefore, the major portion of this essay will be devoted to the impact of one piece of work on the biomedical community. I hope that this kind of presentation will inspire other members of the editorial board to come forward and offer a review of the implications and applications of their work following its publication in eCAM. It is reassuring to publish after rigorous peer review and even more gratifying if our work receives sufficient acclaim and influence to affect the intellectual growth and biological well-being of a discipline, a society, a culture. Influence through good work for mankind is one way to define quality of life (QoL), although it is often associated with healing properties.

$e C A M$ 's fundamental task of carrying out the crucial, but nonetheless ambitious, mission of bridging east-west medicine's divide - portrayed in the journal's cover - will soon celebrate its first 5 years. The pursuit of alternative and complementary - conventional and traditionalmedical scientific principles and therapies backed by 
evidence is depicted in the pages of our journal, with a scientific effort that coincides with and affirms our past achievements and engenders a yearning for present and future challenges. Such is the virtue of our journal's timeless vocation and its youthful age.

Among the body of work is Jose Olalde's novel Systemic Theory of Living Systems (ST), a philosophically approached and scientifically evidenced theory that was published in four articles in 2005 (1-4) and received the editor-in-chief's feedback $(5,6)$. ST established principles for the incorporation of phytonutraceuticals for the treatment of chronic degenerative diseases. ST has received substantial international interest in various gatherings: First International Congress on Systemic Medicine (SM) in Venezuela (7); David Geffen School of Medicine, UCLA (8); First International Congress on Complementary and Alternative Treatments on Cancer in Madrid (9); Integrative Medicine-Royal College of Physicians in London (10); National Assembly of Venezuela; Center for Integrative Medical Studies of Cuba and Autonomous University of Guadalajara Mexico. One of its formulations 'Circulat', patented in USA and Russia as an antidiabetic lesions amputation formula, was the subject of a gene expression study, validating ST's synergistic and molecular action (11).

This has not escaped the attention of health authorities in Russia, Cuba and Venezuela, where programs targeting diabetic foot are being investigated for application in public health centers. Lastly, the Universidad de Guadalajara (Mexico) is presently promoting an agreement to foster a post-graduate degree in SM. SM has to date treated over 1 million patients in Venezuela and Puerto Rico, with well over $90 \%$ clinical success and enhancement of QoL.

\section{Acknowledgement}

I acknowledge with pleasure the advice and substantial contribution to this editorial of Oswaldo del Castillo, after consultation with editorial board member Jose Olalde Rangel.

\section{References}

1. Olalde J. The systemic theory of living systems and relevance to CAM: part I: the theory. Evid Based Complement Alternat Med 2005;1:13-8.

2. Olalde J. The systemic theory of living systems and relevance to CAM: the theory (part II). Evid Based Complement Alternat Med 2005;2:129-37.

3. Olalde J. The systemic theory of living systems and relevance to CAM. Part III: the theory. Evid Based Complement Alternat Med 2005;2:267-75.

4. Olalde J, Magarici M, Amendola F, del Castillo O. The systemic theory of living systems. Part IV: systemic medicine-the praxis. Evid Based Complement Alternat Med 2005;3:429-39.

5. Cooper EL. Complementary and alternative medicine: challenge to eCAM. Evid Based Complement Alternat Med 2006;3:1-2.

6. Cooper EL. ECAM is waiting for eCAM. Evid Based Complement Alternat Med 2005;2:427-8.

7. Olalde J, del Castillo O. First international congress on systemic medicine, gas discharge visualization (GDV) and electrooncotherapy (ECT): report, Caracas, January 21-22. Evid Based Complement Alternat Med 2005;2:255-6.

8. Cooper EL, Hecht SB. Exploring natural products: workshop report, Los Angeles, April 19, 2005. Evid Based Complement Alternat Med 2005;2:409-10.

9. Campoy JA, Muro A. Closing of the first international congress on complementary and alternative treatments in cancer. Evid Based Complement Alternat Med 2005;2:411-12.

10. Magarici M. [Systemic Medicine acceptance at London's Royal College of Physicians] 2007. http://www.adaptogeno.com/svms/ noticias/noticia239.asp.

11. Antoshechkin A, Olalde J, Magarici M, Salom A, Suarez J, Amendola F. Analysis of effects of the herbal preparation circulat on gene expression levels in cultured human fibroblasts. Phytotherapy 2007;21:777-89. 


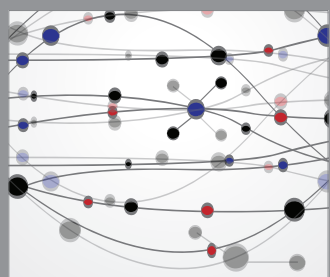

The Scientific World Journal
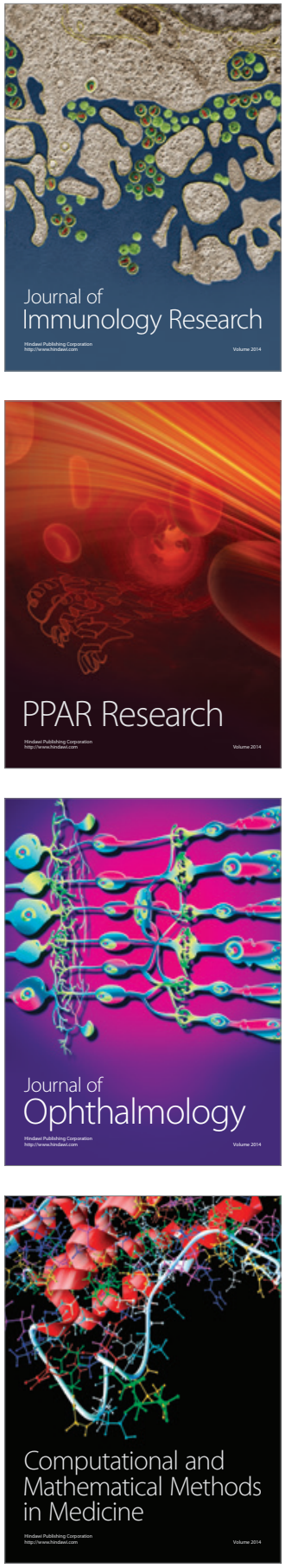

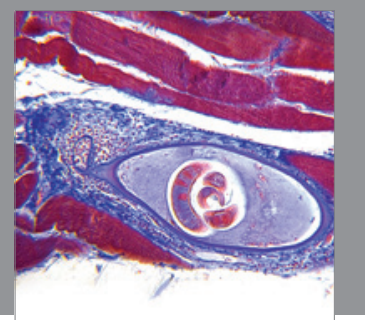

Gastroenterology

Research and Practice
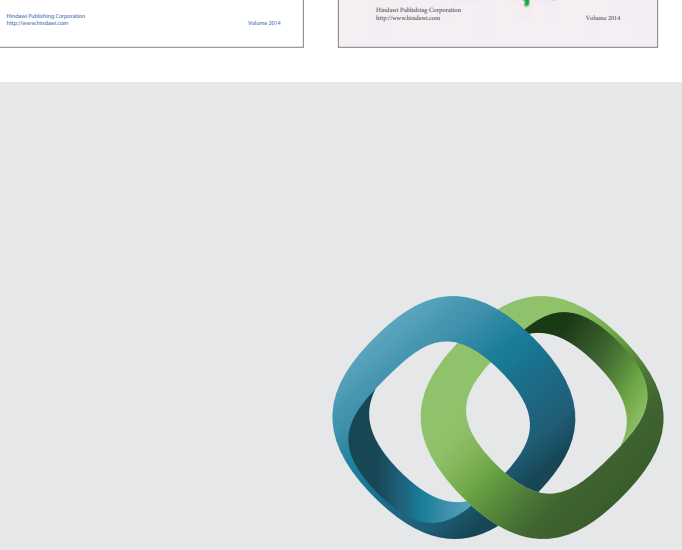

\section{Hindawi}

Submit your manuscripts at

http://www.hindawi.com
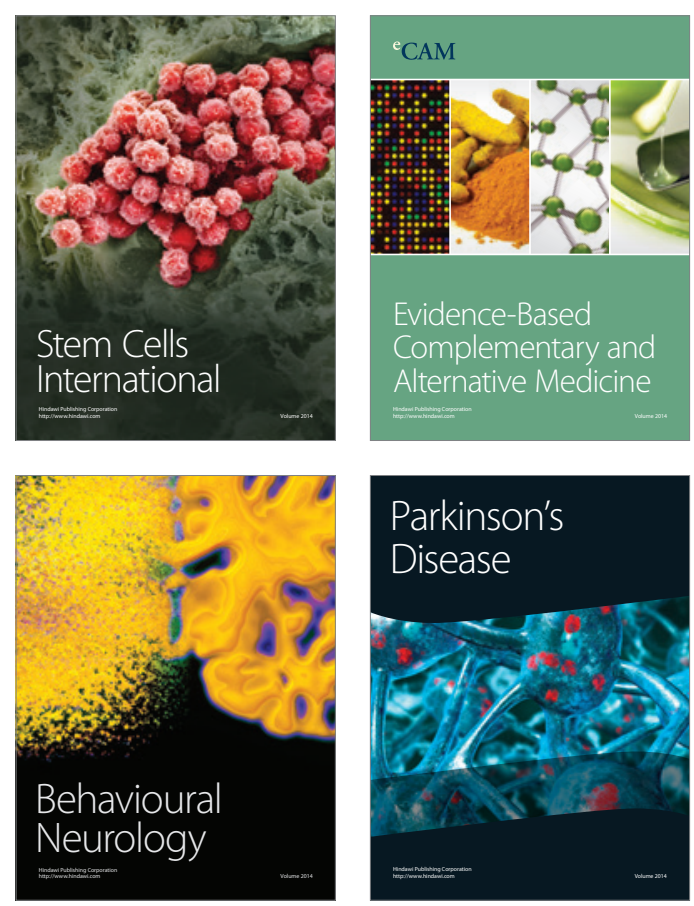

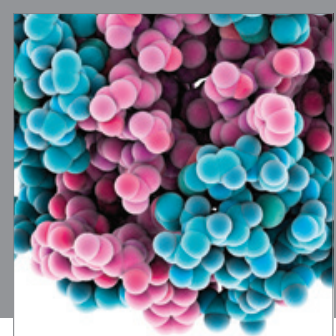

Journal of
Diabetes Research

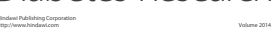

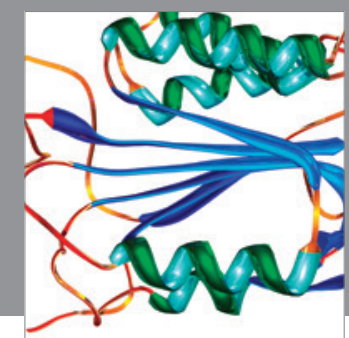

Disease Markers
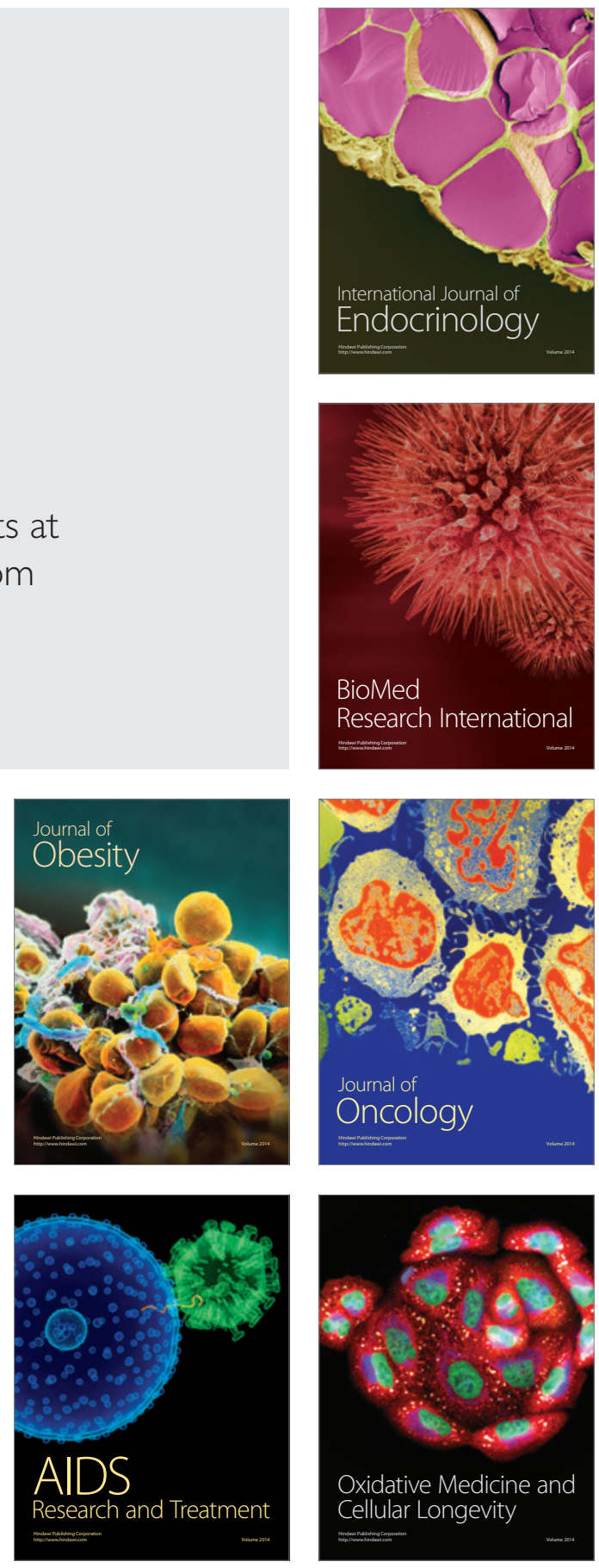